\title{
THE ROLE OF THE STATE IN FORMING THE INNOVATIVE ECONOMICS: THE CASE OF GEORGIA
}

\section{SALOME DANELIA}

\section{PhD Student}

Ivane Javakhishvili Tbilisi State University, Georgia

salome.danelia@tsu.ge

Abstract. The modern paradigm of economic development shows that an important factor affecting the economic development is not only natural resources, but also innovative approaches that stimulate the competitiveness of the country. Forming the innovative economics in the direction of education, trade, investment and financial decentralization requires the selection of effective tools of innovative economics formation, which creates fertile foundation for the introduction of innovations in these areas. And this is achieved by optimal coordination of different combinations of state regulation instruments.

Relevance of the topic: Determining the importance of the role of state in forming the innovative economics and developing the concept of national innovation system is connected with the scientists-economists of the neoclassical school of the 90 s of the last century. However, apart from theoretical assessments, no complex research has been conducted in this direction.

Scientific novelty of the research: The article outlines the main directions of forming the innovative economics based on the identification and analysis of the factors affecting the innovative economics. The need for the involvement of state institutions in the process of forming an innovative economy is also substantiated in this article.

KEYWORDS: NATIONAL INNOVATION SYSTEM, GLOBAL INNOVATION INDEX, KNOWLEDGE-BASED ECONOMY, GLOBAL COMPETITIVENESS INDEX, INTERNATIONAL PROPERTY RIGHTS INDEX, GROSS DOMESTIC PRODUCT, RESEARCH AND DEVELOPMENT.

For citation: Danelia, S. (2021). The Role of the State in Forming the Innovative Economics: The Case of Georgia. Globalization and Business. 12, 45-51. https://doi.org/10.35945/gb.2021.12.005

\section{INTRODUCTION}

The purpose of this article is to define the role of the state in the process of forming an innovative economics.

The study's object is the problems related to forming the innovative economics in Georgia.

The study's subject is to determine the factors affecting the innovative economics and conceptual analysis of state involvement.

The works of Georgian and foreign scientists are the theoretical-methodological bases of the innovative economics research. And the publications of the following professors are noteworthy among Georgian scientists: A. Silagadze (2013), V. Papava (2018), G. Gaganidze (2016), R. Gvelesiani (2014), E. Mekvabishvili (2016), S. Gelashvili (2014), R. Abesadze (2016), L. Bakhtadze (2019), G. Bedianashvili (2017), Sh. Veshapidze (2014).

Among the foreign scientists, the fundamental works of the following authors are of great importance: I. Schumpeter (1942), R. Solow (2957), K. Freeman (1995; 2002; 2008), B. A. Lundvali (2007), R. Nelson (1993), K. Pavit (1984) et al.

The study is also founded on the materials and Legislative Acts of the World Bank, National Statistics Office of Georgia, Georgian and Foreign Profile Ministries on the research topic.

The paper uses research analysis, synthesis and other methods.
Theoretical-methodological foundations of innovative economics

The word "Innovation" means the creation of something new and a qualitative change. "Creating new" and "innovation" are synonymous, but they have different meanings. In particular, "Innovation" is the result of the development of a new scientific idea and innovative activity, while the "Creation of new" is the process of introducing innovation. The word "Innovation" expresses both the process of activity and its result.

According to the World Bank, "Innovation" 1 is a process of new technologies and methods that can bring significant benefits to society. Putting innovation into practice is of great importance, as new technologies and methods significantly improve both the existing product and the production process and services.

The modern methodology of innovation is based on the modern standards developed in Oslo in 1992 that are used to classify technological innovations. The classification of innovations is carried out in relation to the activities of an individual field, in which the following types of innovation are outlined: technological, informational, organizationalmanagerial, etc.

At the present stage, innovation is an important fac- 
tor of economic growth, which affects the structure of production, the social situation of the country and ensures the stabilization of the socio-economic situation in the country. Innovative economics in its substantive sense provides an effective link between education, scientific research and business innovation based on knowledge and scientific-technical progress.

In the 20s of the last century, the first innovation observations were made by the Russian economist N. Kondratiev, who discovered the so-called "Long waves" in the economy. These waves are created by the introduction of baseline determinative novelties that, in turn, give stimulus to the use of many secondary and comprehensive innovations. N. Kondratiev attributed the innovations to the cumulative elements that define economic development.

There is another point of view, according to which innovative economics means "knowledge-based economy." It considers the professional-technical training of workers and raising the qualification in accordance with the requirements of the labor market. Great importance is also given to supporting the development of innovative thinking and the formation of an innovative, knowledge-based society.

The word „Innovation" as a new economic category was first used by the Austrian economist Josef Alois Schumpeter (Schumpeter, J.A. 1883-1950), who developed N. Kondratiev's theory on innovation.

N. Kondratiev and I. Schumpeter recognize industrial innovation as the driving force of economic growth in their main works. They view the impact of institutional factors on the structure of innovative activities as new combinations of changes in economic development and consider the cyclical nature of the economy as a pattern of economic growth.

According to I. Schumpeter, "Innovation is a commercialized invention." It is a factor that accelerates public welfare and economic growth. It should be noted that through innovations based on scientific and technical knowledge more economic wealth is created at low cost that increases production efficiency and labor productivity.

I, Schumpeter in his work "Capitalism, Socialism and Democracy" relies on the idea according to which the driving force of economic progress is "Creative destruction", that means replacing old business models, products and professions with new ones. He believes that "Creative destruction" and the creation of new things are prerequisites for economic development.

Achieving innovative economic development is possible only through establishment of an appropriate economic system, development of science, industrial and agrarian sectors, improvement of sectoral and social structures (Abesadze, 2016).

The technological progress and innovative, creative thinking are often attributed to private companies and small firms; while the state with its regulatory function and tax system is considered as a disruptive power to the above. However, all the projects that are the basis of modern technologies are funded by the state. The state gives impetus to innovation and invests in it. It is the first to enter the new market, when "risky" private companies, despite adequate resources, become active only when the foundation has already been laid and major work has been done. The state implements the above-mentioned through the resources at its disposal and taxes, the reduction of which, in the long run, has a negative impact on public welfare and the benefits of innovation fall into the hands of only a small group of people.

\section{National Innovation System}

One of the forms of innovative economics, in particular scientific and technical development was formed during the Soviet era, in the 50 s of XX century. Off course, the model of the Soviet Union was different from the modern models of economic development, but it is noteworthy that knowledge was transforming and becoming an important priority of state policy during that period.

The implementation and support of economic activities, focused on knowledge and introduction of new technologies in parallel with traditional production factors, are important for developing countries like Georgia. This implies the formation and implementation of the innovative economics development strategy by both central and regional governments.

It is believed that the creation, dissemination and adoption of technologies initially reduces economic growth rates and productivity levels (due to integration and restructuring problems). However, the technological innovation is seen as a major driving force of economic growth due to the improvement of productivity levels and, ultimately, the acceleration of economic growth in the long run. Some of the scientists are quite critical of the relationship between invention and national economic growth. They believe that the lowest economic growth is in countries that invest heavily in new technologies, while the countries that introduce new technologies are characterized by higher economic growth.

In the early 1990s, the name of the scientists-economists of the neoclassical school was connected with the development of the concept of national innovation systems. It is a combination of institutional, economic and social factors. In addition to the term "National innovation", the following terms are used to define the formation of an innovation economics by the state: regional economic system, sectoral innovation system and global innovation system. The concept of national innovation economics is based on the fact that the creation and dissemination of new knowledge, technologies are carried out through the interaction of state, private and public organizations.

According to many economists, the concept of a national innovation system is a key factor in forming innovation economics. The British economist Christopher Freeman made a significant contribution to the revival of the neo-Schumpeterian tradition. He argues: "Scientific research suggests that economics has evolved from the despair of science into an economy of hope" (Freeman, 1992).

National innovation is defined in different ways. K. Freeman describes it as "The unity of public and private institutions through whose activities and interactions new technologies are created". According to P. Patel and K. Pavitt (Patel \& Pavitt, 1994), national institutions determine the quality 
Table 1. Factors of the National Innovation System

\begin{tabular}{|l|c|}
\hline Universities (Scientific researches) & Research institutes (Technological development) \\
\hline Private companies (Commercialization) & State (Legislative framework, institutions and \\
support programs)
\end{tabular}

and direction of technological education within the country. S. Metcalfe (Metcalfe, 1995) believed that institutions, collectively and individually, contribute to the development and dissemination of new technologies, while governments develop and implement innovative process policies that define new knowledge and technologies. After that R. Nelson (1995) and Lundwall (1992) developed theoretical views about national innovation systems.

Thus, the national innovation system includes four interrelated factors:

As usual, innovation policy of a country is defined by the state. The innovation development strategy should be in line with the country's socio-economic development strategy and program.

Identifying the role of the state in the process of forming an innovative economics can be done in different ways, particularly (table 1):

- Through regulatory tools (institutions, legislation and support programs);

- By research institutes (technological development) and universities (scientific research);

- Through private companies (commercialization).

It should be noted that creating a legal framework for the formation of an innovative economics in Georgia began in the 90 s of last century. The regulatory instruments and legislative norms developed by the state to promote the development of an innovative economics in Georgia are supported and approved by the state (table 2 ).

State regulation mechanism for the formation of an innovative economics for the country is considered to be a

Table 2. Legislative, institutional and state support

\begin{tabular}{|l|l|}
\hline Year & Legislative, institutional and state support \\
\hline 1994 & Law of Georgia on "Science, Technology and their Development". \\
\hline 1999 & Patent Law of Georgia. \\
\hline 2004 & Law of Georgia on "Higher Education". \\
\hline 2005 & Law of Georgia on "General Education". \\
\hline 2007 & "On Vocational Education". \\
\hline 2010 & LEPL "Shota Rustaveli National Science Foundation". \\
\hline 2014 & "Georgia's Innovation and Technology Agency". \\
\hline 2014 & State Program “Produce in Georgia”. \\
\hline 2015 & "Research and Innovation Council chaired by the Prime Minister". \\
\hline 2015 & Strategy “Innovative Georgia 2020. \\
\hline 2016 & The Law of Georgia on Innovation. \\
\hline
\end{tabular}

key condition for the formation of an innovation economics.

Over the last decade, the issue of forming an innovative economics has become a priority area of the state interests which is evidenced by the formation of a legal basis for innovation, on the basis of which the building the an innovative economics, the development of a national innovation system is carried out. The mentioned ensures the smooth implementation of the whole innovation cycle (science-invention-production), where the main role is played by the market, and the state regulates the referred processes.

The selection of regulatory methods and tools depends on the level of economic development and the measures that the state is able to implement.

The second component is research institutes (technological development) and universities (scientific research) that can be generalized as economic policy instruments.

The second component, economic policy instruments, includes state subsidies, fiscal incentives, implementation of state programs, and so on. It covers research and development expenses (R\&D), the number of researchers (figure 1), tax stimulus measures, credit, fiscal and monetary leverage, and implementation of measures to attract foreign direct investments. The state policy envisages the mobilization of factors in the initial stage of business, the introduction and absorption of new technologies, the creation of innovative infrastructure, the most common forms of which are: techno parks, business incubators, innovation-technological centers, training-business centers, etc. The part of the economic instruments also includes the ways to enhance knowledge, competence, and issues on funding and organizing the trainings and seminars.

The figure 1 shows a 5-year trend in research and development (R\&D) expenses and the number of scientists involved in research. The table shows a growing trend.

The grants issued by the state to fund research, in particular the grant programs of the Rustaveli Foundation and the Georgia's Innovation and Technology Agency, are considered to be a determinant of the growing trend.

Based on increased spending by the state on scientific research and development, South Korea has been able to fund science for about $200 \%$ over 40 years, while research and development spending in relation to gross domestic product has increased by $35 \%$. South Korea managed to form an innovative economics based on the support of a knowledge-based economy. They invested a considerable amount of money in the education system and the works of scientists, which put South Korea in the category of developed countries. 
Figure 1. Research and development expenses and the number of researchers involved

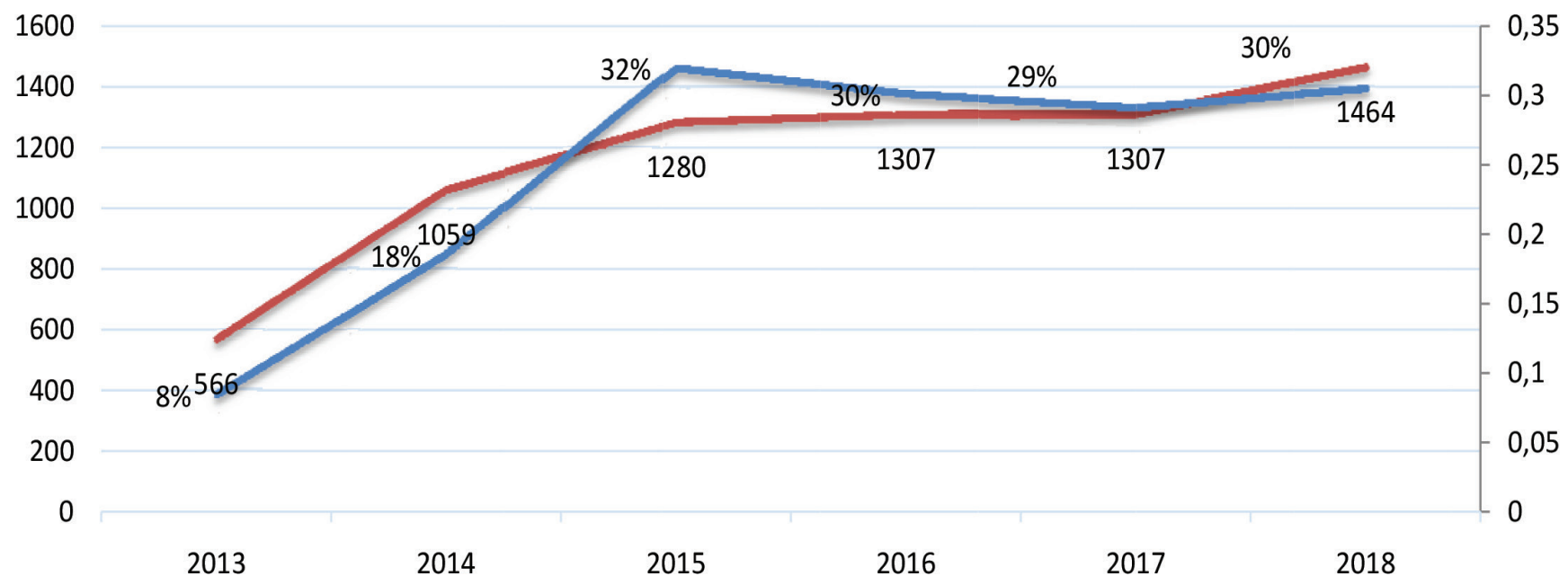

Researchers (per million people) — $\quad$ Research and development expenses (\% of GDP)

Source: World Bank www.worldbank.org/

Private companies (commercialization) - State involvement in the implementation of subsidies to stimulate the use of innovation and technology. The state can mobilize the high-risk and long-term sources of funding needed to develop innovation. Unlike the state, private investors are driven by more short-term and speculative goals, which hinders the long-term development process required to create radical technologies. The success of innovation and growth of many companies is based on new technological knowledge, the initial capital and infrastructure of which are created by the state. This section also includes the transfer of knowledge from universities to the private sector.

The role of the state in forming the innovative economics in the context of institutional composition review

It is necessary to define the role of state institutions in the process of establishing the system of innovative economics and analyze the state institutions, on the basis of which we will identify the needs and problems of state institutions regarding to the formation of an innovative economics.

The formation of the innovative economics involves research institutes, universities, investors, institutions supporting innovative ecosystems, business incubators that enable entrepreneurs with innovative ideas to develop their own business ideas under the favorable conditions. The amount of funding for research and development is determined by the Parliament of Georgia during the review of the state budget.

The following ministries play an important role in forming the innovative economics policy:

Ministry of Education and Science of Georgia - is responsible for improving the "knowledge-based economy", one of the directions of the formation of an innovation economics. In particular, it involves the regulation of the research and development system. Also, the Shota Rustaveli National Science Foundation of Georgia, established on the basis of the Ministry, promotes the development of science, technology and innovation system in the country.
Ministry of Economy and Sustainable Development of Georgia - the ministry is responsible for the formulation of social and economic development strategy and building innovation-based economy. The Georgia's Innovation and Technology Agency, under the Ministry of Economy and Sustainable Development of Georgia, has been established to develop an innovation ecosystem. In addition, National Intellectual Property Center of Georgian "Sakpatenti" has been established on the basis of the Ministry of Economy and Sustainable Development of Georgia, which defines the intellectual property policy.

Ministry of Environment and Natural Resources Protection of Georgia - the Ministry contributes to the formation of an innovative economics by transitioning to sustainable development.

The Ministry of Finance of Georgia - the ministry pays a significant attention to the tax incentives and state subsidies, when defining the budgeting and tax policy, in order to support the introduction of innovations in the production process.

Ministry of energy of Georgia - the function of the Ministry in the process of forming an innovative economics is revealed in the process of creating non-traditional energy resources, in particular renewable energy resources.

Positions in international rankings are an important indicator for assessing the current processes in the economic, social and political environment of the country. In order to determine the positioning of the main instruments of Georgia's innovative economy, we will review Georgia's positions in international rankings, on the bases of which several international indexes are reviewed below.

Global Innovation Index (GII), which assesses the innovation capacity of up to 131 countries and presents the latest global innovation trends, on the basis of Global innovation index data helps and give recommendations to the countries on creating the environment needed for innovation devel- 
Table 3. Georgia in international rankings

\begin{tabular}{|l|c|}
\hline Indicators (position of Georgia) & $2019-2020$ \\
\hline Global Innovation Index (GII) & 63 \\
\hline Global Competitiveness Index (GCI) & 66 \\
\hline Intellectual Property Rights Index & 73 \\
\hline
\end{tabular}

opment. Georgia is ranked 63rd position with 31.78 points (from 100). The global innovation index relies on two sub-indexes: the innovation input and innovation output, according to which Georgia ranks 54th with 43.89 points, in terms of innovation expenditures and 71st position with 19.66 points in terms of production.

Figure 2 clearly shows the innovation rate according to the data of the last ten years. According to the given ratings, the innovation index from 2014 to 2016 is almost growing, and from 2016 to 2020 a different trend is observed. Georgia had the highest rate in 2019, it was among the top 50 countries and ranked 48th position. The main indicators of Georgia's significant success are high-tech imports, while exports of Information and Communication Services (ICT) decreased, though, at the same time, the rating among the countries was increasing. The mentioned may be due to the slow pace of innovation development compared to other countries.

\section{Global Competitiveness Index (GCI)}

In contrast to the indexes discussed above, the Global Competitiveness Index $(\mathrm{GCl})$ measures both conditions of public institutions, the stability of macroeconomic environment, and its level of technological readiness. This index is determined by the World Economic Forum. The ranking in the Global Competitiveness Index is based on publicly available (statistical) data (World Bank; International Monetary Fund, World Health Organization, etc.) and the results of surveys conducted by World Economic Forum executives. The specificity of the research lies in obtaining the data needed for the research through questionnaires from the business sector. The survey, based on the Global Competitiveness Index, covers 141 countries, with Georgia ranking 74th (61 total points) position. In 2018, a survey was conducted on 140 countries, where Georgia ranked 66th. Accordingly, the rating of Georgia, compared to the previous year, has deteriorated by 8 points in the Global Competitiveness Index.

An economy that is growing rapidly over time is considered competitive. It should be noted that in 2019 , compared to 2018 , the country has not shown positive progress in any direction.

Based on the global indexes discussed, we can identify the main problems in the formation of an innovative economics. Above mentioned indexes are calculated by different mechanisms. And in order to clearly present the situation in the country, we need to begin by describing the functions of existing institutional organizations.

\section{International Property Rights Index}

The International Property Rights Index (IPRI) assesses the institutions that define property rights: the legal and political environment, physical property, and intellectual property rights. It is the only index in the world that fully measures intellectual and physical property rights. It covers 129 countries and provides information on property rights systems that affect 98 percent of the world's GDP and 94 percent of the world's population. This index also assesses the level of successful economy and building a just society. In addition, since 2020, the index will examine the close

Table 4. Georgia in the Global Innovation Index

\begin{tabular}{|c|c|c|c|c|c|c|}
\hline & $\begin{array}{c}\text { Georgia in the } \\
\text { Global Innovation } \\
\text { Index. Rank. }\end{array}$ & $\begin{array}{c}\text { Georgia in the Global } \\
\text { Innovation Index. } \\
\text { Score (0-100) }\end{array}$ & $\begin{array}{c}\text { Innovation } \\
\text { input. } \\
\text { Rank. }\end{array}$ & $\begin{array}{c}\text { Innovation input. } \\
\text { Score (0-100) }\end{array}$ & $\begin{array}{c}\text { Innovation output. } \\
\text { Rank }\end{array}$ & $\begin{array}{c}\text { Innovation output. } \\
\text { Score (0-100) }\end{array}$ \\
\hline 2020 & 63 & 31.78 & 54 & 43.89 & 71 & 19,66 \\
\hline
\end{tabular}

Figure 2. Georgia according to the Global Innovation Index 2011-2020

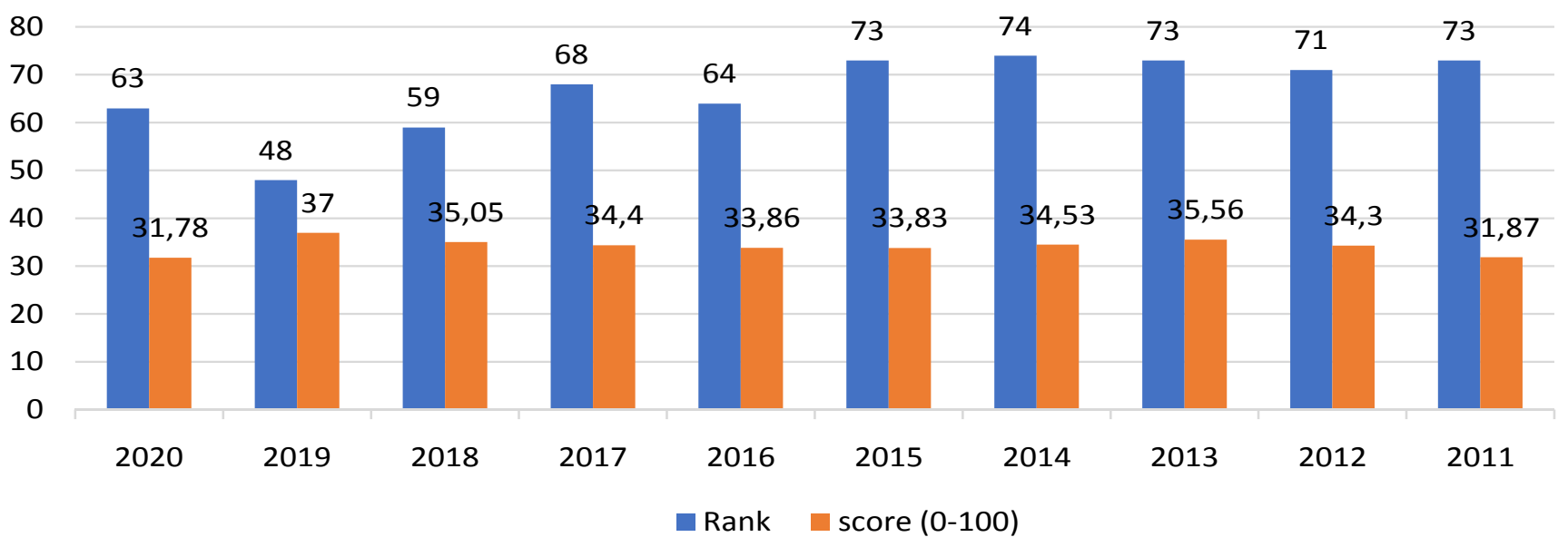

Source: https://www.globalinnovationindex.org/analysis-indicator 
Figure 3. Rating of Georgia in 2011-2019

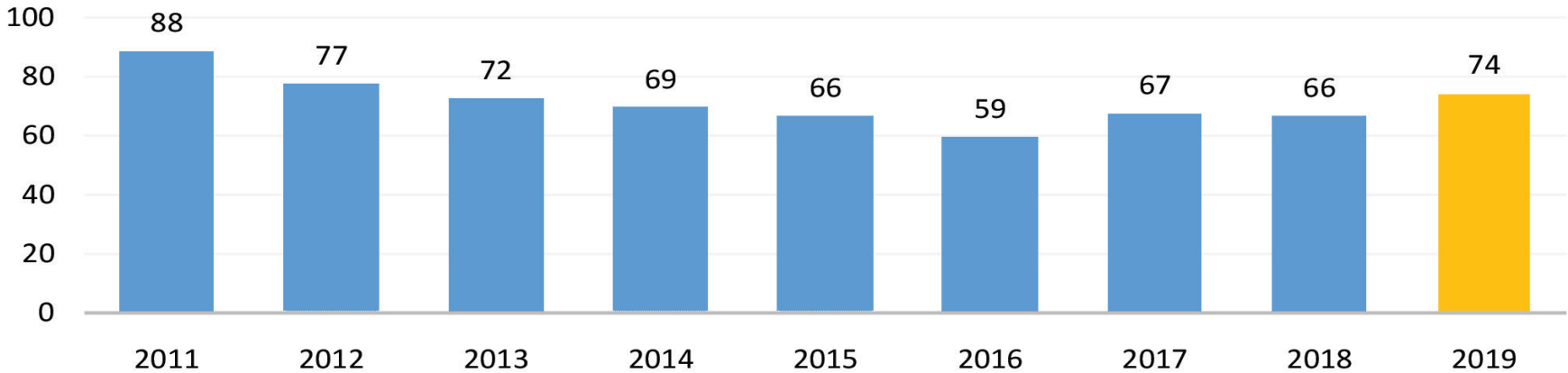

Source: the reports of Global Innovation Index (2011-2019).

relationship between property rights and other economic and social indicators of well-being, including: gender equality, entrepreneurship, research and development, personality development, civic activism and access to information communications.

According to 2020 data, Georgia ranks 73rd out of 129 countries in the International Property Rights Index (IPRI), and in the region - (Eastern Europe and Central Asia) 14th out of 25 countries.

According to Figure 4, it is clear that Georgia's rating in the International Property Rights Index (IPRI) is increasing according to the data of the last ten years.

Accordingly, rating of Georgia in the International Property Rights Index (IPRI), from year to year, indicates a positive attitude towards the property rights regime and quality of life.

\section{CONCLUSION}

The active formation of innovation policies makes it possible to lay the groundwork for reform.

Innovative economics also implies high-tech development. Although, we think that unequivocal assertion that high technology is the main guarantee of economic development of the country is incorrect. In such a case, we consider the knowledge as a more important factor, because high technol- ogy may not create wealth and jobs, while the development of low technology and the use of local knowledge may lead to significant economic growth and improved prosperity. The use of high technology in all kinds of products, processes and services can be more important than its production.

The post-industrial era can be called a cognitive revolution, which today has taken the form of a knowledge economy. The current situation is characterized by very rapid scientific and technical development. Advances in science allow the use of a wide range of new methods and technologies in the field and activity that require new skills and new types of knowledge. More flexibility of higher education, politics and institutions are needed in order to take advantage of the innovative potential of such achievements and to lay the foundations for a so-called knowledge economy.

Although benefits are provided for innovative entrepreneurial structures within the framework of the operation of venture funds, techno parks and business incubators, their volume is not sufficient for the sustainable development of an innovative company. In this regard, it is necessary to involve higher education institutions in the development of innovations, they will assist economic entities and government agencies in solving problems by developing innovations. Resolving this issue is quite a difficult task and requires systematic work in which both the state as well as the academic and industrial sectors must be involved.

Figure 4. Rating of Georgia in 2011-2020

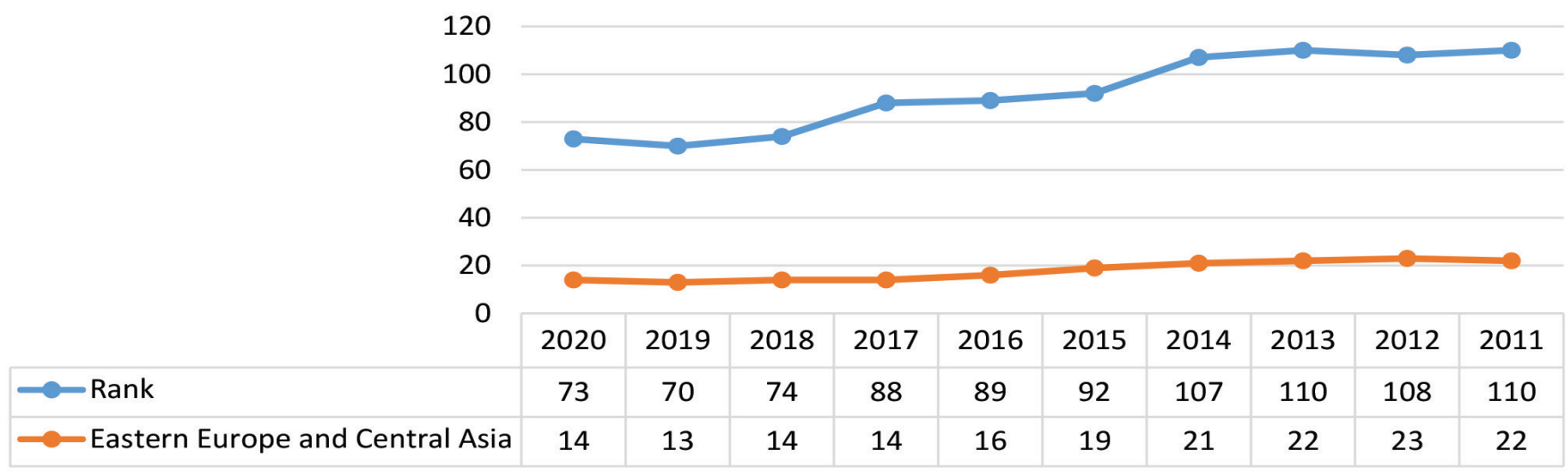

- Rank —Eastern Europe and Central Asia 
We believe that the absence of research institutes, scientific laboratories, business incubators, scientific teams and laboratories and the renewal of outdated material and technical bases of the former institutions of the academy are particularly important for Georgia. While the formation of a knowledge-based economy is the main basis for the development of an innovative economics. To ensure this, institutional and legal changes have begun in the country. Accordingly, it is important to prioritize increasing spending on education in relation to GDP.

Furthermore, in our opinion, the main factor in the formation of the country's innovative economics is human capital, which is formed on the basis of investments in education. Human capital formation is founded on the massive investments in education, healthcare, provision of information, which together ensure the growth and development of human creativity skills.

The general directions of the formation of an innovative economy in Georgia can be formulated as follows:

1. The importance of the interaction between business, the state and the academic sector for the formation of an innovative economics must be clearly understood. Innovation policies and strategies also need to be developed. In particular, to establish a coordinating agency that will facilitate the development of innovation policies necessary for the formation of an innovative economics, which will clearly describe the strategy for the implementation of innovation policies. it will be a public policy document, the implementation of which will be entrusted to the relevant public institutions;

2. Gradual implementation of effective measures for the integration of the Georgian science and education system into the Common European Space and the development of cooperation in the field of research activities with the friend countries of the region;

3. The trend developed in the modern world taken into account by the state;

4. Development of innovative infrastructure, which includes the creation of business incubators, provision of workspace and technology transfer center for the institutes of innovative activities, evaluation of the commercial potential of innovation, as well as the establishment of mechanisms to facilitate the dissemination of technologies;

5. Formation and development of research-based innovation system. At this stage, expenditures on the development of scientific research do not reach $1 \%$ of GDP. More support is needed in this direction from the state;

6. Protection of intellectual property and improvement of the related legislative and institutional framework.

Thus, in the light of foregoing, the formation of an innovation system together with theoretical research is possible on the basis of effective management of the processes of forming the innovative economics by the state.

\section{REFERENCES:}

Abesadze, R. (2016). Innovations - a key factor in economic development. The Collection of the International Scientific-Practical Conference Materials: Current Problems in the Economics and Development of Economic Science. Tbilisi, TSU, Publishing House of Paata Gugushvili Institute of Economics.

Bakhtadze, L., \& Danelia, S. (2019). The Major Determinants of Innovative Environment Formation in Georgia. Economic Alternatives, University of National and World Economy, Sofia, Bulgaria. 2, 243-249.

Bedianishvili, G. (2017). Formation of Knowledge Economy and Innovative Entrepreneurship Policy: Institutional Aspects. Globalization and Business. 3, 10-16.

Danelia, S. (2020). The Importance of Knowledge-Based Economy Index in Georgia. Journal of Economics. 6-9, 54-68.

Freeman, C. (1995). The National Innovation Systems in historical perspective. Cambridge Journal of Economics, 19(1), 22-33.

Freeman, C. (2002). Continental, national and sub-national innovation systems complementarity and economic growth. Research Policy. 31, 191-211.

Freeman, C. (2008). Innovation and long cycles of economic development', Edward Elgar Publishing. 19(1), 5-29.

Gaganidze, G. (2016). Export potential and competitive advantage. BESSH, 77(6), 12.

Gvelesiani, R. (2014). The main reasons for distancing from the reality of the concept of economic policy and the possibilities of their elimination. Economics and Business. 9(3), 11-24.

Lundvall, A. (2007). National Innovation Systems. Analytical Concept and Development Tool. Industry \& Innovation. $14,95-119$.

Nelson, R. (1993). National Innovation Systems: A Comparative Study. Oxford: Oxford University Press;

OECD (1997). National Innovation Systems. Paris: OECD.

Papava, V. (2018). Downward and backward growth - the experience of EU post-communist countries and Georgia.

Pavitt, K. (1984). Sectoral patterns of technical change: Towards a taxonomy', Research Policy. 13, 343-373.

Schumpeter, J. A. (1942). Capitalism, Socialism, and Democracy. New York: Harper and Brothers.

Silagadze, A. (2013). Modern Economic Aspects of Georgia. Business-Injectioning. 4, 143-149.

Solow, R. (1957). Technical Change and the Aggregate Production Functions. Review of Economics and Statistics. 39, 312-320. 